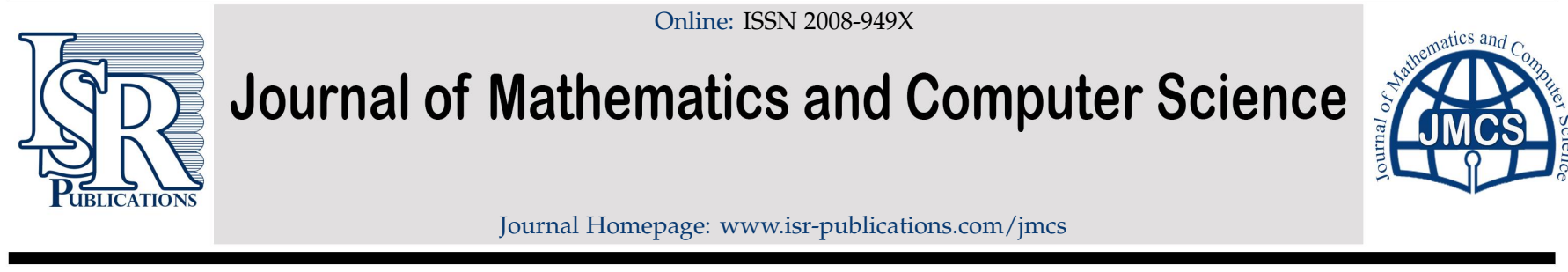

\title{
A modified extra-gradient method for a family of strongly pseudomonotone equilibrium problems in real Hilbert spaces
}

\author{
Habib ur Rehman ${ }^{\mathrm{a}}$, Nuttapol Pakkaranang ${ }^{\mathrm{a}}$, Azhar Hussain ${ }^{\mathrm{b}}$, Nopparat Wairojjana ${ }^{\mathrm{c}, *}$ \\ ${ }^{a}$ KMUTTFixed Point Research Laboratory, KMUTT-Fixed Point Theory and Applications Research Group, SCL 802 Fixed Point \\ Laboratory, Department of Mathematics, Faculty of Science, King Mongkut's University of Technology Thonburi (KMUTT), 126 \\ Pracha-Uthit Road, Bang Mod, Thrung Khru, Bangkok 10140, Thailand. \\ ${ }^{b}$ Department of Mathematics, University of Sargodha, Sargodha-40100, Pakistan. \\ ${ }^{c}$ Applied Mathematics Program, Faculty of Science and Technology, Valaya Alongkorn Rajabhat University under the Royal Patronage \\ (VRU), 1 Moo 20 Phaholyothin Road, Klong Neung, Klong Luang, Pathumthani, 13180, Thailand.
}

\begin{abstract}
In this paper, we propose a modified extragradient method for solving a strongly pseudomonotone equilibrium problem in a real Hilbert space. A strong convergence theorem relative to our proposed method is proved and the proposed method has worked without having the information of a strongly pseudomonotone constant and the Lipschitz-type constants of a bifunction. We have carried out our numerical explanations to justify our well-established convergence results, and we can see that our proposed method has a substantial improvement over the time of execution and number iterations.
\end{abstract}

Keywords: Equilibrium problem, strongly pseudomonotone bifunction, strong convergence theorem, Lipschitz-type conditions, variational inequality problems.

2020 MSC: 47J25, 47H09, 47H06, 47J05.

(C)2021 All rights reserved.

\section{Introduction}

Let $\mathrm{K}$ to be a nonempty closed, convex subset of a Hilbert space $\mathbb{E}$ and $f: \mathbb{E} \times \mathbb{E} \rightarrow \mathbb{R}$ be a bifunction such that $f(x, x)=0$ for all $x \in K$. The equilibrium problem for the bifunction $f$ on $K$ is defined as follows:

$$
\text { Find } x^{*} \in K \text { such that } f\left(x^{*}, y\right) \geqslant 0, \forall y \in K \text {. }
$$

Equilibrium problem (EP) was initially established in the unique format by Blum and Oettli [8] in 1994 and provided a comprehensive study on their theoretical properties. This study consists of considerable improvement in applied and pure science. It had been previously presented that the equilibrium problem

\footnotetext{
${ }^{*}$ Corresponding author

Email addresses: hrehman.hed@gmail.com.com (Habib ur Rehman), nuttapol.pak@mail.kmutt.ac.th (Nuttapol

Pakkaranang), hafiziqbal30@yahoo.com (Azhar Hussain), nopparat@vru.ac.th (Nopparat Wairojjana)

doi: $10.22436 /$ jmcs.022.01.04
}

Received: 2020-03-19 Revised: 2020-04-10 Accepted: 2020-04-27 
theory has set up a unique approach to deal with many topics that are arisen from the social sciences, economics, finance, restoration of image, ecology, transport, networking, elasticity and optimization problems (see for details $[3,10,11,20,28]$ ). The equilibrium problem contains several mathematical problems as particular cases, i.e., minimization problems, variational inequality problems (VIP), the fixed point problems, the Nash equilibrium of non-cooperative games, complementarity problems, the problem of vector minimization and the saddle point problem $[8,13,19,21,34]$.

On the other hand, iterative methods are significant and useful tools for studying the numerical solution of an equilibrium problem. A considerable number of methods was formed to deal with specific types of equilibrium problems for finite and infinite dimensional spaces (see $[9,12,14,17,18,24,25,27$, $29,32,33])$. More specifically, Hieu et al. in [15] described a sequence $\left\{x_{n}\right\}$ recursively as:

$$
\left\{\begin{array}{l}
x_{0} \in K, \\
y_{n}=\arg \min \left\{\lambda_{n} f\left(x_{n}, y\right)+\frac{1}{2}\left\|x_{n}-y\right\|^{2}: y \in K\right\}, \\
x_{n+1}=\arg \min \left\{\lambda_{n} f\left(y_{n}, y\right)+\frac{1}{2}\left\|x_{n}-y\right\|^{2}: y \in K\right\}
\end{array}\right.
$$

where $\left\{\lambda_{n}\right\}$ is a sequence of positive real numbers satisfy the following conditions, i.e.,

$$
\left(\Psi_{1}\right): \lim _{n \rightarrow \infty} \lambda_{n}=0 \text { and }\left(\Psi_{2}\right): \sum_{n=0}^{\infty} \lambda_{n}=+\infty .
$$

On the other hand, inertial-type methods are valuable and depending on the technique of the heavyball methods of the second-order time dynamic system. Polyak started by considering an inertial step as an acceleration process to deal with the problem of smooth convex minimization. Inertial-type methods are two-step iterative programs and the next iteration is determined by using the previous two iterations and may be used the accelerated step to boost up the iterative sequence (further details, see $[1,2,6,23$, $30,31,35])$.

In this paper, on the basis of the work of Hieu et al. [15], we propose a modified extragradient method for solving equilibrium problems involving bifunction $f$ being strongly pseudomonotone. Our purpose method is carried out without any knowledge of the lipschitz-type and strongly pseudomonotone constants of the bifunction. This modification is based on the use of a step-size sequence that slowly converges to zero and is non-summable. Due to this factor and the strong pseudomonotonicity of the bifunction, the strong convergence of our method has been achieved. Despite that, it is not mandatory to have the information about these constants before, i.e., such constants should not be within the input parameters of the method. In the end, the numerical experiments are carried out and shown that proposed method is more efficient than the existing ones $[15,16]$ in term of number of iteration and execution time.

The paper is arranged according to the following. Section 2 provides definitions and essential lemmas which are used during this paper. Section 3 consists of our proposed method and corresponding strong convergence theorem. Section 4 sets out the numerical experimental work to indicate the numerical performance compared to existing methods.

\section{Preliminaries}

We take $\mathrm{K}$ convex and closed subset of a Hilbert space $\mathbb{E}$. The notion $\langle.,$.$\rangle and \|$.$\| views for the inner$ product and norm on the Hilbert space, respectively. Moreover, $\operatorname{EP}(f, K)$ stands for the solution set of an equilibrium problem over the set $\mathrm{K}$ and $\mathrm{VI}(\mathrm{G}, \mathrm{K})$ solution set of an variational inequality problem over the set $K$ with $x^{*}$ is any arbitrary member of $E P(f, K)$ or $V I(G, K)$.

Let $\mathrm{g}: \mathrm{K} \rightarrow \mathbb{R}$ is a convex function and subdifferential of $\mathrm{g}$ at $\mathrm{x} \in \mathrm{K}$ is defined as follows:

$$
\partial g(x)=\{z \in \mathbb{E}: g(y)-g(x) \geqslant\langle z, y-x\rangle, \forall y \in K\} .
$$

A normal cone of $\mathrm{K}$ at $\mathrm{x} \in \mathrm{K}$ is given as

$$
\mathrm{N}_{\mathrm{K}}(x)=\{z \in \mathbb{E}:\langle z, y-x\rangle \leqslant 0, \forall y \in K\} .
$$


Definition $2.1([7,8]) . f: \mathbb{E} \times \mathbb{E} \rightarrow \mathbb{R}$ on $K$ for $\gamma>0$ is

(i) strongly monotone if

$$
f(x, y)+f(y, x) \leqslant-\gamma\|x-y\|^{2}, \forall x, y \in K ;
$$

(ii) monotone if

$$
f(x, y)+f(y, x) \leqslant 0, \forall x, y \in K
$$

(iii) strongly pseudomonotone if

$$
f(x, y) \geqslant 0 \Longrightarrow f(y, x) \leqslant-\gamma\|x-y\|^{2}, \forall x, y \in K ;
$$

(iv) pseudomonotone if

$$
f(x, y) \geqslant 0 \Longrightarrow f(y, x) \leqslant 0, \forall x, y \in K ;
$$

(v) satisfying the Lipschitz-type condition on $\mathrm{K}$ if there are $\mathrm{k}_{1}, \mathrm{k}_{2}>0$, such that

$$
f(x, z) \leqslant f(x, y)+f(y, z)+k_{1}\|x-y\|^{2}+k_{2}\|y-z\|^{2}, \forall x, y, z \in K .
$$

Lemma 2.2 ([26]). Let $\mathrm{K}$ be a nonempty, closed and convex subset of a real Hilbert space $\mathbb{E}$ and $\mathrm{g}: \mathrm{K} \rightarrow \mathbb{R}$ be a subdifferentiable, convex and lower semicontinuous function on $\mathrm{K}$. Moreover, $\mathrm{x} \in \mathrm{K}$ is a minimizer of a function $\mathrm{g}$ if and only if $0 \in \partial \mathrm{g}(\mathrm{x})+\mathrm{N}_{\mathrm{K}}(\mathrm{x})$, where $\partial \mathrm{g}(\mathrm{x})$ and $\mathrm{N}_{\mathrm{K}}(\mathrm{x})$ stand for the subdifferential of $\mathrm{g}$ at $\mathrm{x}$ and the normal cone of $\mathrm{K}$ at $\mathrm{x}$, respectively.

Lemma $2.3([4])$. Assume $a_{n}, b_{n}$ and $c_{n}$ are sequences in $[0,+\infty)$ such that

$$
a_{n+1} \leqslant a_{n}+b_{n}\left(a_{n}-a_{n-1}\right)+c_{n} \text {, for all } n \geqslant 1 \text {, with } \sum_{n=1}^{+\infty} c_{n}<+\infty,
$$

and also with $\mathrm{b}>0$ such that $0 \leqslant \mathrm{~b}_{\mathrm{n}} \leqslant \mathrm{b}<1$, for all $\mathrm{n} \in \mathbb{N}$. Thus, the following relations are true.

(i) $\sum_{n=1}^{+\infty}\left[a_{n}-a_{n-1}\right]_{+}<\infty$, with $[s]_{+}:=\max \{s, 0\}$;

(ii) $\lim _{n \rightarrow+\infty} a_{n}=a^{*} \in[0, \infty)$.

Lemma 2.4 ([5]). For every $\alpha, \beta \in \mathbb{E}$ and $\mu \in \mathbb{R}$, the following item is true:

$$
\|\mu \alpha+(1-\mu) \beta\|^{2}=\mu\|\alpha\|^{2}+(1-\mu)\|\beta\|^{2}-\mu(1-\mu)\|\alpha-\beta\|^{2} .
$$

Lemma 2.5 ([22]). Suppose $\left\{\alpha_{n}\right\}$ and $\left\{\beta_{n}\right\}$ be two sequences of nonnegative real numbers. If $\sum_{n=1}^{\infty} \alpha_{n}=\infty$, and $\sum_{n=1}^{\infty} \alpha_{n} \beta_{n}<\infty$, thus $\liminf _{n \rightarrow \infty} \beta_{n}=0$.

Assumption 1. Let $f: \mathbb{E} \times \mathbb{E} \rightarrow \mathbb{R}$ satisfying the following conditions:

(f1) $f(x, x)=0$, for all $x \in K$ and $f$ is strongly pseudomonotone on $K$;

(f2) f satisfy the Lipschitz-type conditions through two positive constants $k_{1}$ and $k_{2}$;

(f3) $f(x,$.$) is sub-differentiable and convex on K$ for each fixed $x \in K$.

\section{An algorithm and its strong convergence analysis}

We established an inertial method for dealing with strongly pseudomonotone equilibrium problem with a Lipschitz-type condition. However, it is not compulsory to have information about the Lipschitztype constants $k_{1}, k_{2}$ and strongly pseudomonotone constant $\gamma$ previously to generate the iterative sequence. The following is our method in detail.

Algorithm 3.1 (Modified extragradient method for strongly pseudomonotone equilibrium problems).

Initialization: Choose $x_{-1}, x_{0} \in \mathbb{E}$ and $0 \leqslant \theta_{n}<\sqrt{5}-2$. 
Iterative steps: Assume $x_{n-1}, x_{n}$ are known for $n \geqslant 0$, and a sequence $\left\{\lambda_{n}\right\}$ satisfying the conditions:

$$
\left(T_{1}\right): \lim _{n \rightarrow \infty} \lambda_{n}=0 \text { and }\left(T_{2}\right): \sum_{n=1}^{\infty} \lambda_{n}=+\infty \text {. }
$$

Step 1: Compute

$$
y_{n}=\underset{y \in K}{\arg \min }\left\{\lambda_{n} f\left(w_{n}, y\right)+\frac{1}{2}\left\|w_{n}-y\right\|^{2}\right\}
$$

where $w_{n}=x_{n}+\theta_{n}\left(x_{n}-x_{n-1}\right)$. If $y_{n}=w_{n}$ then stop and $w_{n}$ is the solution of the equilibrium problem. Otherwise, go to Step 2.

Step 2: Compute

$$
x_{n+1}=\underset{y \in K}{\arg \min }\left\{\lambda_{n} f\left(y_{n}, y\right)+\frac{1}{2}\left\|w_{n}-y\right\|^{2}\right\} .
$$

Set $n:=n+1$ and go back to Step 1.

Lemma 3.2. From Algorithm 3.1, we have the following useful inequality.

$$
\lambda_{n} f\left(y_{n}, y\right)-\lambda_{n} f\left(y_{n}, x_{n+1}\right) \geqslant\left\langle w_{n}-x_{n+1}, y-x_{n+1}\right\rangle, \forall y \in K .
$$

Proof. By Lemma 2.2, we can write

$$
0 \in \partial_{2}\left\{\lambda_{n} f\left(y_{n}, y\right)+\frac{1}{2}\left\|w_{n}-y\right\|^{2}\right\}\left(x_{n+1}\right)+N_{K}\left(x_{n+1}\right) .
$$

Thus, for $\omega \in \partial_{2} f\left(y_{n}, x_{n+1}\right)$ and $\bar{\omega} \in N_{K}\left(x_{n+1}\right)$ we have

$$
\lambda_{n} \omega+x_{n+1}-w_{n}+\bar{\omega}=0 .
$$

The above implies that

$$
\left\langle w_{n}-x_{n+1}, y-x_{n+1}\right\rangle=\lambda_{n}\left\langle\omega, y-x_{n+1}\right\rangle+\left\langle\bar{\omega}, y-x_{n+1}\right\rangle, \forall y \in K .
$$

Since $\bar{\omega} \in N_{K}\left(x_{n+1}\right)$ then $\left\langle\bar{\omega}, y-x_{n+1}\right\rangle \leqslant 0$, for all $y \in K$. Thus, we obtain

$$
\left\langle w_{n}-x_{n+1}, y-x_{n+1}\right\rangle \leqslant \lambda_{n}\left\langle\omega, y-x_{n+1}\right\rangle, \forall y \in K .
$$

By $\omega \in \partial f\left(y_{n}, x_{n+1}\right)$, we get

$$
f\left(y_{n}, y\right)-f\left(y_{n}, x_{n+1}\right) \geqslant\left\langle\omega, y-x_{n+1}\right\rangle, \forall y \in K .
$$

Combining (3.1) and (3.2) we get the required result

$$
\lambda_{n} f\left(y_{n}, y\right)-\lambda_{n} f\left(y_{n}, x_{n+1}\right) \geqslant\left\langle w_{n}-x_{n+1}, y-x_{n+1}\right\rangle, \forall y \in K
$$

Lemma 3.3. By Algorithm 3.1, we can also get the following inequality.

$$
\lambda_{n} f\left(w_{n}, y\right)-\lambda_{n} f\left(w_{n}, y_{n}\right) \geqslant\left\langle w_{n}-y_{n}, y-y_{n}\right\rangle, \forall y \in K
$$

Proof. It follows the same procedure as in Lemma 3.2.

Lemma 3.4. Let $\mathrm{f}: \mathrm{K} \rightarrow \mathbb{R}$ satisfies the Assumption 1 and the solution set $\mathrm{EP}(\mathrm{f}, \mathrm{K}) \neq \emptyset$. Thus, for each $x^{*} \in$ $\operatorname{EP}(f, K)$, we have

$$
\left\|x_{n+1}-x^{*}\right\|^{2} \leqslant\left\|w_{n}-x^{*}\right\|^{2}-\left(1-2 k_{1} \lambda_{n}\right)\left\|w_{n}-y_{n}\right\|^{2}-\left(1-2 k_{2} \lambda_{n}\right)\left\|y_{n}-x_{n+1}\right\|^{2}-2 \gamma \lambda_{n}\left\|y_{n}-x^{*}\right\|^{2} .
$$


Proof. By the Lemma 3.2 and replacing $y=x^{*}$, we have

$$
\lambda_{n} f\left(y_{n}, x^{*}\right)-\lambda_{n} f\left(y_{n}, x_{n+1}\right) \geqslant\left\langle w_{n}-x_{n+1}, x^{*}-x_{n+1}\right\rangle .
$$

Since $f\left(x^{*}, y_{n}\right) \geqslant 0$ then due to strong pseudomonotonicity implies that $f\left(y_{n}, x^{*}\right) \leqslant-\gamma\left\|y_{n}-x^{*}\right\|^{2}$, such that

$$
\left\langle w_{n}-x_{n+1}, x_{n+1}-x^{*}\right\rangle \geqslant \lambda_{n} f\left(y_{n}, x_{n+1}\right)+\gamma \lambda_{n}\left\|y_{n}-x^{*}\right\|^{2} .
$$

The Lipschitz-type continuity of a bifunction $f$ leads to

$$
f\left(w_{n}, x_{n+1}\right) \leqslant f\left(w_{n}, y_{n}\right)+f\left(y_{n}, x_{n+1}\right)+k_{1}\left\|w_{n}-y_{n}\right\|^{2}+k_{2}\left\|y_{n}-x_{n+1}\right\|^{2} .
$$

Combining the expression (3.3) and (3.4) we obtain

$$
\begin{aligned}
\left\langle w_{n}-x_{n+1}, x_{n+1}-x^{*}\right\rangle \geqslant & \lambda_{n}\left\{f\left(w_{n}, x_{n+1}\right)-f\left(w_{n}, y_{n}\right)\right\}-k_{1} \lambda_{n}\left\|w_{n}-y_{n}\right\|^{2} \\
& -k_{2} \lambda_{n}\left\|y_{n}-x_{n+1}\right\|^{2}+\gamma \lambda_{n}\left\|y_{n}-x^{*}\right\|^{2} .
\end{aligned}
$$

Following Lemma 3.3 with $y=x_{n+1}$, we have

$$
\lambda_{n} f\left(w_{n}, x_{n+1}\right)-\lambda_{n} f\left(w_{n}, y_{n}\right) \geqslant\left\langle w_{n}-y_{n}, x_{n+1}-y_{n}\right\rangle \text {. }
$$

By the expression (3.5) and (3.6) we get

$$
\begin{aligned}
\left\langle w_{n}-x_{n+1}, x_{n+1}-x^{*}\right\rangle \geqslant & \left\langle w_{n}-y_{n}, x_{n+1}-y_{n}\right\rangle-k_{1} \lambda_{n}\left\|w_{n}-y_{n}\right\|^{2} \\
& -k_{2} \lambda_{n}\left\|y_{n}-x_{n+1}\right\|^{2}+\gamma \lambda_{n}\left\|y_{n}-x^{*}\right\|^{2} .
\end{aligned}
$$

Furthermore, we have the following facts:

$$
\begin{aligned}
-2\left\langle w_{n}-x_{n+1}, x_{n+1}-x^{*}\right\rangle & =-\left\|w_{n}-x^{*}\right\|^{2}+\left\|x_{n+1}-w_{n}\right\|^{2}+\left\|x_{n+1}-x^{*}\right\|^{2}, \\
2\left\langle y_{n}-w_{n}, y_{n}-x_{n+1}\right\rangle & =\left\|w_{n}-y_{n}\right\|^{2}+\left\|x_{n+1}-y_{n}\right\|^{2}-\left\|w_{n}-x_{n+1}\right\|^{2} .
\end{aligned}
$$

From above two facts and (3.7) we get the desired result.

$$
\left\|x_{n+1}-x^{*}\right\|^{2} \leqslant\left\|w_{n}-x^{*}\right\|^{2}-\left(1-2 k_{1} \lambda_{n}\right)\left\|w_{n}-y_{n}\right\|^{2}-\left(1-2 k_{2} \lambda_{n}\right)\left\|y_{n}-x_{n+1}\right\|^{2}-2 \gamma \lambda_{n}\left\|y_{n}-x^{*}\right\|^{2} .
$$

Theorem 3.5. The sequences $\left\{x_{n}\right\},\left\{y_{n}\right\}$, and $\left\{w_{n}\right\}$ generated by Algorithm 3.1 converge strongly to $x^{*} \in \operatorname{EP}(f, K)$, where $0 \leqslant \theta_{n} \leqslant \theta<\sqrt{5}-2$.

Proof. Due to $\lambda_{n} \rightarrow 0$ there is an $N_{0} \in \mathbb{N}$ such that for each $n \geqslant N_{0}$, we have

$$
0<\lambda_{n} \leqslant \frac{\frac{1}{2}-2 \theta-\frac{1}{2} \theta^{2}-\tau}{\max \left\{k_{1}, k_{2}\right\}(1-\theta)^{2}} \text { for some } 0<\tau<\frac{1}{2}-2 \theta-\frac{1}{2} \theta^{2} .
$$

Thus, Lemma 3.4 for $n \geqslant N_{0}$, provides that

$$
\begin{aligned}
\left\|x_{n+1}-x^{*}\right\|^{2} & \leqslant\left\|w_{n}-x^{*}\right\|^{2}-\left(1-\beta \lambda_{n}\right)\left[\left\|w_{n}-y_{n}\right\|^{2}+\left\|x_{n+1}-y_{n}\right\|^{2}\right] \\
& \leqslant\left\|w_{n}-x^{*}\right\|^{2}-\frac{\left(1-\beta \lambda_{n}\right)}{2}\left\|x_{n+1}-w_{n}\right\|^{2},
\end{aligned}
$$

where $\beta=\max \left\{2 \mathrm{k}_{1}, 2 \mathrm{k}_{2}\right\}$. By Lemma 2.4 , we obtain

$$
\left\|w_{n}-x^{*}\right\|^{2}=\left(1+\theta_{n}\right)\left\|x_{n}-x^{*}\right\|^{2}-\theta_{n}\left\|x_{n-1}-x^{*}\right\|^{2}+\theta_{n}\left(1+\theta_{n}\right)\left\|x_{n}-x_{n-1}\right\|^{2},
$$

and

$$
\left\|x_{n+1}-w_{n}\right\|^{2}=\left\|x_{n+1}-x_{n}-\theta_{n}\left(x_{n}-x_{n-1}\right)\right\|^{2}
$$




$$
\begin{aligned}
& =\left\|x_{n+1}-x_{n}\right\|^{2}+\theta_{n}^{2}\left\|x_{n}-x_{n-1}\right\|^{2}-2 \theta_{n}\left\langle x_{n+1}-x_{n}, x_{n}-x_{n-1}\right\rangle \\
& \geqslant\left\|x_{n+1}-x_{n}\right\|^{2}+\theta_{n}^{2}\left\|x_{n}-x_{n-1}\right\|^{2}-2 \theta_{n}\left\|x_{n+1}-x_{n}\right\|\left\|x_{n}-x_{n-1}\right\| \\
& \geqslant\left\|x_{n+1}-x_{n}\right\|^{2}+\theta_{n}^{2}\left\|x_{n}-x_{n-1}\right\|^{2}-\theta_{n}\left\|x_{n+1}-x_{n}\right\|^{2}-\theta_{n}\left\|x_{n}-x_{n-1}\right\|^{2} \\
& =\left(1-\theta_{n}\right)\left\|x_{n+1}-x_{n}\right\|^{2}+\left(\theta_{n}^{2}-\theta_{n}\right)\left\|x_{n}-x_{n-1}\right\|^{2} .
\end{aligned}
$$

Combining the expressions (3.8), (3.9), and (3.11) we obtain

$$
\begin{aligned}
\left\|x_{n+1}-x^{*}\right\|^{2} \leqslant & \left(1+\theta_{n}\right)\left\|x_{n}-x^{*}\right\|^{2}-\theta_{n}\left\|x_{n-1}-x^{*}\right\|^{2}+\theta_{n}\left(1+\theta_{n}\right)\left\|x_{n}-x_{n-1}\right\|^{2} \\
& -\rho_{n}\left(1-\theta_{n}\right)\left\|x_{n+1}-x_{n}\right\|^{2}-\rho_{n}\left(\theta_{n}^{2}-\theta_{n}\right)\left\|x_{n}-x_{n-1}\right\|^{2} \\
= & \left(1+\theta_{n}\right)\left\|x_{n}-x^{*}\right\|^{2}-\theta_{n}\left\|x_{n-1}-x^{*}\right\|^{2}-\rho_{n}\left(1-\theta_{n}\right)\left\|x_{n+1}-x_{n}\right\|^{2} \\
& +\left[\theta_{n}\left(1+\theta_{n}\right)-\rho_{n}\left(\theta_{n}^{2}-\theta_{n}\right)\right]\left\|x_{n}-x_{n-1}\right\|^{2} \\
= & \left(1+\theta_{n}\right)\left\|x_{n}-x^{*}\right\|^{2}-\theta_{n}\left\|x_{n-1}-x^{*}\right\|^{2}-q_{n}\left\|x_{n+1}-x_{n}\right\|^{2}+r_{n}\left\|x_{n}-x_{n-1}\right\|^{2},
\end{aligned}
$$

where $\rho_{\mathfrak{n}}:=\frac{\left(1-\beta \lambda_{n}\right)}{2} \geqslant 0$ and $q_{n}:=\rho_{n}\left(1-\theta_{n}\right) \geqslant 0$ with

$$
r_{n}:=\theta_{n}\left(1+\theta_{n}\right)-\rho_{n}\left(\theta_{n}^{2}-\theta_{n}\right)=\theta_{n}\left(1+\theta_{n}\right)+\rho_{n} \theta_{n}\left(1-\theta_{n}\right) \geqslant 0 \text {, for all } n \geqslant N_{0} \text {. }
$$

Next, we assume that

$$
\Pi_{n}=\left\|x_{n}-x^{*}\right\|^{2}-\theta_{n}\left\|x_{n-1}-x^{*}\right\|^{2}+r_{n}\left\|x_{n}-x_{n-1}\right\|^{2} .
$$

By using the expression (3.13) we can evaluate the following for $n \geqslant N_{0}$, such that

$$
\begin{aligned}
\Pi_{n+1}-\Pi_{n}= & \left\|x_{n+1}-x^{*}\right\|^{2}-\theta_{n+1}\left\|x_{n}-x^{*}\right\|^{2}+r_{n+1}\left\|x_{n+1}-x_{n}\right\|^{2} \\
& -\left\|x_{n}-x^{*}\right\|^{2}+\theta_{n}\left\|x_{n-1}-x^{*}\right\|^{2}-r_{n}\left\|x_{n}-x_{n-1}\right\|^{2} \\
\leqslant & \left\|x_{n+1}-x^{*}\right\|^{2}-\left(1+\theta_{n}\right)\left\|x_{n}-x^{*}\right\|^{2}+\theta_{n}\left\|x_{n-1}-x^{*}\right\|^{2} \\
& +r_{n+1}\left\|x_{n+1}-x_{n}\right\|^{2}-r_{n}\left\|x_{n}-x_{n-1}\right\|^{2} \\
\leqslant & -\left(q_{n}-r_{n+1}\right)\left\|x_{n+1}-x_{n}\right\|^{2}
\end{aligned}
$$

and

$$
\begin{aligned}
\mathrm{q}_{\mathrm{n}}-\mathrm{r}_{\mathrm{n}+1} & =\rho_{\mathrm{n}}\left(1-\theta_{\mathrm{n}}\right)-\theta_{\mathrm{n}+1}\left(1+\theta_{\mathrm{n}+1}\right)+\rho_{\mathrm{n}+1}\left(\theta_{\mathrm{n}+1}^{2}-\theta_{\mathrm{n}+1}\right) \\
& \geqslant \rho_{\mathrm{n}+1}\left(1-\theta_{\mathrm{n}+1}\right)-\theta_{\mathrm{n}+1}\left(1+\theta_{\mathrm{n}+1}\right)+\rho_{\mathfrak{n}+1}\left(\theta_{\mathrm{n}+1}^{2}-\theta_{\mathrm{n}+1}\right) \\
& \geqslant \rho_{\mathrm{n}+1}(1-\theta)^{2}-\theta-\theta^{2} \\
& =\left(\frac{1}{2}-\frac{\beta}{2} \lambda_{n+1}\right)(1-\theta)^{2}-\theta-\theta^{2} \\
& =\left(\frac{1}{2}-2 \theta-\frac{1}{2} \theta^{2}\right)-\frac{\beta}{2} \lambda_{n+1}(1-\theta)^{2} \geqslant \tau .
\end{aligned}
$$

From the expression (3.14) and (3.15) we obtain

$$
\Pi_{n+1}-\Pi_{n} \leqslant-\tau\left\|x_{n+1}-x_{n}\right\|^{2} \leqslant 0 .
$$

Hence the sequence $\left\{\Pi_{n}\right\}$ is non-increasing for $n \geqslant N_{0}$. The definition of $\left\{\Pi_{n}\right\}$ for $n \geqslant N_{0}$, implies that

$$
\begin{aligned}
\left\|x_{n}-x^{*}\right\|^{2} & \leqslant \Pi_{n}+\theta_{n}\left\|x_{n-1}-x^{*}\right\|^{2} \\
& \leqslant \Pi_{N_{0}}+\theta\left\|x_{n-1}-x^{*}\right\|^{2} \\
& \leqslant \cdots \leqslant \Pi_{n_{0}}\left(\theta^{n-N_{0}}+\cdots+1\right)+\theta^{n-N_{0}}\left\|x_{N_{0}}-x^{*}\right\|^{2}
\end{aligned}
$$




$$
\leqslant \frac{\Pi_{\mathrm{N}_{0}}}{1-\theta}+\theta^{\mathrm{n}-\mathrm{N}_{0}}\left\|\mathrm{x}_{\mathrm{N}_{0}}-x^{*}\right\|^{2}
$$

By the definition of $\left\{\Pi_{n+1}\right\}$ for $n \geqslant N_{0}$, with expression (3.17) implies that

$$
-\Pi_{n+1} \leqslant \theta_{n+1}\left\|x_{n}-x^{*}\right\|^{2} \leqslant \theta\left\|x_{n}-x^{*}\right\|^{2} \leqslant \theta \frac{\Pi_{N_{0}}}{1-\theta}+\theta^{n-N_{0}+1}\left\|x_{N_{0}}-x^{*}\right\|^{2} .
$$

It follows from expressions (3.16) and (3.18) such that

$$
\tau \sum_{n=N_{0}}^{k}\left\|x_{n+1}-x_{n}\right\|^{2} \leqslant \Pi_{N_{0}}-\Pi_{k+1} \leqslant \Pi_{N_{0}}+\theta \frac{\Pi_{N_{0}}}{1-\theta}+\theta^{k-N_{0}+1}\left\|x_{N_{0}}-x^{*}\right\|^{2} \leqslant \frac{\Pi_{N_{0}}}{1-\theta}+\left\|x_{N_{0}}-x^{*}\right\|^{2},
$$

letting $k \rightarrow \infty$ in expression (3.19) implies that

$$
\sum_{n=1}^{\infty}\left\|x_{n+1}-x_{n}\right\|^{2}<+\infty \Longrightarrow \lim _{n \rightarrow \infty}\left\|x_{n+1}-x_{n}\right\|=0 .
$$

Thus, the expression (3.10) with (3.20) implies that

$$
\left\|\mathrm{x}_{\mathrm{n}+1}-w_{\mathrm{n}}\right\| \rightarrow 0 \text { as } \mathrm{n} \rightarrow \infty .
$$

By expression (3.12), (3.20) with Lemma 2.3, implies that

$$
\lim _{n \rightarrow \infty}\left\|x_{n}-x^{*}\right\|^{2}=l \text { and } \lim _{n \rightarrow \infty}\left\|w_{n}-x^{*}\right\|^{2}=l
$$

To show $\lim _{n \rightarrow \infty}\left\|y_{n}-x^{*}\right\|^{2}=l$, next, we use Lemma 3.4, for $n \geqslant N_{0}$ with relations (3.21) and (3.22) such that

$$
\begin{aligned}
\left(1-2 k_{1} \lambda_{n}\right)\left\|w_{n}-y_{n}\right\|^{2} & \leqslant\left\|w_{n}-x^{*}\right\|^{2}-\left\|x_{n+1}-x^{*}\right\|^{2} \\
& =\left(\left\|w_{n}-x^{*}\right\|+\left\|x_{n+1}-x^{*}\right\|\right)\left(\left\|w_{n}-x^{*}\right\|-\left\|x_{n+1}-x^{*}\right\|\right) \\
& \leqslant\left(\left\|w_{n}-x^{*}\right\|+\left\|x_{n+1}-x^{*}\right\|\right)\left\|x_{n+1}-w_{n}\right\| \longrightarrow 0, \text { as } n \rightarrow \infty .
\end{aligned}
$$

This implies that, the sequences $\left\{x_{n}\right\},\left\{w_{n}\right\}$, and $\left\{y_{n}\right\}$ are bounded for each $x^{*} \in \operatorname{EP}(f, K)$, and the $\lim _{n \rightarrow \infty}\left\|x_{n}-x^{*}\right\|$ exists. We prove $\left\{x_{n}\right\}$ strongly converges to $x^{*}$. By Lemma 3.4, with (3.9) for $n \geqslant N_{0}$, we have

$$
\begin{aligned}
2 \gamma \lambda_{n}\left\|y_{n}-x^{*}\right\|^{2} \leqslant & -\left\|x_{n+1}-x^{*}\right\|^{2}+\left(1+\theta_{n}\right)\left\|x_{n}-x^{*}\right\|^{2}-\theta_{n}\left\|x_{n-1}-x^{*}\right\|^{2}+\theta_{n}\left(1+\theta_{n}\right)\left\|x_{n}-x_{n-1}\right\|^{2} \\
\leqslant & \left(\left\|x_{n}-x^{*}\right\|^{2}-\left\|x_{n+1}-x^{*}\right\|^{2}\right)+\theta(1+\theta)\left\|x_{n}-x_{n-1}\right\|^{2} \\
& +\left(\theta_{n}\left\|x_{n}-x^{*}\right\|^{2}-\theta_{n-1}\left\|x_{n-1}-x^{*}\right\|^{2}\right) .
\end{aligned}
$$

Now summing up above expression for $k>N_{0}$, we obtain

$$
\begin{aligned}
\sum_{n=N_{0}}^{k} 2 \gamma \lambda_{n}\left\|y_{n}-x^{*}\right\|^{2} \leqslant & \left(\left\|x_{N_{0}}-x^{*}\right\|^{2}-\left\|x_{k+1}-x^{*}\right\|^{2}\right)+\theta(1+\theta) \sum_{n=N_{0}}^{k}\left\|x_{n}-x_{n-1}\right\|^{2} \\
& +\left(\theta_{k}\left\|x_{k}-x^{*}\right\|^{2}-\theta_{N_{0}-1}\left\|x_{N_{0}-1}-x^{*}\right\|^{2}\right) \\
\leqslant & \left\|x_{N_{0}}-x^{*}\right\|^{2}+\theta\left\|x_{k}-x^{*}\right\|^{2}+\theta(1+\theta) \sum_{n=N_{0}}^{k}\left\|x_{n}-x_{n-1}\right\|^{2}=M,
\end{aligned}
$$

for $M \geqslant 0$. It gives that

$$
\sum_{n} 2 \gamma \lambda_{n}\left\|y_{n}-x^{*}\right\|^{2}<+\infty
$$


The above expression with Lemma 2.5, implies that

$$
\liminf _{n \rightarrow \infty}\left\|y_{n}-x^{*}\right\|=0 .
$$

Thus, there is a subsequence $\left\{y_{n_{k}}\right\}$ of $\left\{y_{n}\right\}$ such that $\lim _{k \rightarrow \infty}\left\|y_{n_{k}}-x^{*}\right\|=0$. Since $\lim _{n \rightarrow \infty}\left\|x_{n}-y_{n}\right\|=0$, we obtain $\lim _{k \rightarrow \infty}\left\|x_{n_{k}}-x^{*}\right\|=0$. We have $\lim _{n \rightarrow \infty}\left\|x_{n}-x^{*}\right\|=$. Therefore, $\lim _{n \rightarrow \infty}\left\|x_{n}-x^{*}\right\|=0$, i.e., $x_{n} \rightarrow x^{*}, y_{n} \rightarrow x^{*}$ and $w_{n} \rightarrow x^{*}$ as $n \rightarrow \infty$.

Note: If we assume that the bifunction $f(x, y):=\langle G(x), y-x\rangle$ for all $x, y \in K$, then the equilibrium problem converts into the variational inequality problem with $L=2 k_{1}=2 k_{2}$. We deduce the results for a strongly pseudomonotone and Lipschitz continuous operator.

Corollary 3.6. Let $\mathrm{G}: \mathrm{K} \rightarrow \mathbb{E}$ is strongly pseudomonotone with $\mathrm{L}$-Lipschitz continuous on $\mathrm{K}$ for some positive constant $\mathrm{L}>0$ and solution set $\mathrm{VI}(\mathrm{G}, \mathrm{K}) \neq \emptyset$. Let $\left\{w_{n}\right\},\left\{x_{n}\right\},\left\{y_{n}\right\}$ are sequences generated as follows.

(i.) Given $x_{n-1}, x_{n} \in K$ with $w_{n}=x_{n}+\theta_{n}\left(x_{n}-x_{n-1}\right)$ for each $n \geqslant 0$, and $\theta_{n} \in[0, \sqrt{5}-2)$, compute

$$
\left\{\begin{array}{l}
y_{n}=P_{K}\left(w_{n}-\lambda_{n} G\left(w_{n}\right)\right) \\
x_{n+1}=P_{K}\left(w_{n}-\lambda_{n} G\left(y_{n}\right)\right)
\end{array}\right.
$$

where stepsize sequence $\lambda_{n}$ satisfies the conditions

$$
\left(\Psi_{1}\right): \lim _{n \rightarrow \infty} \lambda_{n}=0 \text { and }\left(\Psi_{2}\right): \sum_{n=1}^{\infty} \lambda_{n}=+\infty .
$$

Then, the sequences $\left\{w_{n}\right\},\left\{x_{n}\right\}$, and $\left\{y_{n}\right\}$ strongly converge to $x^{*}$ of $\mathrm{VI}(\mathrm{G}, \mathrm{K})$.

\section{Computational experiment}

We will show some numerical experiments to explain the efficiency of our proposed method. The MATLAB codes run in MATLAB version 9.5 (R2018b) on a PC Intel(R) Core(TM)i5-6200 CPU @ 2.30GHz 2.40GHz, RAM 8.00 GB. We use $x_{-1}=x_{0}=y_{0}=(1,1,1,1,1)^{\top}$, and $y$-axes show $D_{n}$ while the $x$-axis points out to the number of iterations or the time elapsed (in seconds).

\subsection{Nash-Cournot oligopolistic equilibrium model}

Consider that there will be $n$ firms which generate the same commodity. Let $x$ sets for a vector in which each item $x_{i}$ holds for the volume of the commodity generated by a firm $i$. We take the cost $\mathrm{P}$ as a decreasing affine function that depends upon on the subject matter of $S=\sum_{i=1}^{m} x_{i}$, i.e., $P_{i}(S)=\phi_{i}-\psi_{i} S$, where $\phi_{i}>0, \psi_{i}>0$. The profit function for each firm $i$ is defined by $F_{i}(x)=P_{i}(S) x_{i}-t_{i}\left(x_{i}\right)$, where $t_{i}\left(x_{i}\right)$ is the tax value and cost for developing $x_{i}$. Consider that $K_{i}=\left[x_{i}^{\min }, x_{i}^{\max }\right]$ is the set of operations connects to each firm $i$, and the strategy work out for the whole design take the form as $K:=K_{1} \times K_{2} \times \cdots \times K_{n}$. In fact, each firm try to arrive at its peak revenue by adopting the respective stage of production on the assumption that the production of the other firms is an input parameter. A broadly utilized technique to the model is based on the popular Nash equilibrium concept. We would like to point out that point $x^{*} \in \mathrm{K}=\mathrm{K}_{1} \times \mathrm{K}_{2} \times \cdots \times \mathrm{K}_{\mathrm{n}}$ is the point of equilibrium of the model if $\mathrm{F}_{i}\left(x^{*}\right) \geqslant \mathrm{F}_{i}\left(x^{*}\left[x_{i}\right]\right), \forall x_{i} \in \mathrm{K}_{i}, \forall i=$ $1,2, \cdots, n$, with the vector $x^{*}\left[x_{i}\right]$ represent the vector get from $x^{*}$ by taking $x_{i}^{*}$ with $x_{i}$. Certainly, we have $f(x, y):=\varphi(x, y)-\varphi(x, x)$ with $\varphi(x, y):=-\sum_{i=1}^{n} F_{i}\left(x\left[y_{i}\right]\right)$, and the problem of finding the Nash equilibrium point of the model may be as follows:

$$
\text { find } x^{*} \in K: f\left(x^{*}, y\right) \geqslant 0, \forall y \in K \text {. }
$$

It follows from [27], that the bifunction $f$ could be taken in the following form

$$
f(x, y)=\langle A x+B y+c, y-x\rangle,
$$


where $c \in \mathbb{R}^{5}$ and $A, B$ are

$$
A=\left(\begin{array}{ccccc}
3.1 & 2 & 0 & 0 & 0 \\
2 & 3.6 & 0 & 0 & 0 \\
0 & 0 & 3.5 & 2 & 0 \\
0 & 0 & 2 & 3.3 & 0 \\
0 & 0 & 0 & 0 & 3
\end{array}\right), \quad B=\left(\begin{array}{ccccc}
1.6 & 1 & 0 & 0 & 0 \\
1 & 1.6 & 0 & 0 & 0 \\
0 & 0 & 1.5 & 1 & 0 \\
0 & 0 & 1 & 1.5 & 0 \\
0 & 0 & 0 & 0 & 2
\end{array}\right), \quad c=\left(\begin{array}{c}
1 \\
-2 \\
-1 \\
2 \\
-1
\end{array}\right)
$$

$B$ is symmetric positive semidefinite and $B-A$ is symmetric negative definite with Lipschitz constants $k_{1}=k_{2}=\frac{1}{2}\|A-B\|$ (for more details see [27]). The feasible set $K \subset \mathbb{R}^{5}$ is closed and convex and writen as

$$
K:=\left\{x \in \mathbb{R}^{5}:-5 \leqslant x_{i} \leqslant 5\right\} .
$$

The numerical results regarding model 4.1 are shown in Figures 1-6 and Table 1.

\begin{tabular}{|c|c|c|c|c|c|c|c|c|}
\hline \multirow[b]{2}{*}{$\mathrm{n}$} & \multirow[b]{2}{*}{ TOL } & \multirow[b]{2}{*}{$\lambda_{n}$} & \multicolumn{2}{|c|}{ Hieu-Algo1 [15] } & \multicolumn{2}{|c|}{ Hieu-Algo2 [16] } & \multicolumn{2}{|c|}{ Rehman-Algo1 3.1} \\
\hline & & & iter. & time & iter. & time & iter. & time \\
\hline 5 & $10^{-6}$ & $\frac{1}{n+1}$ & 222 & 2.5697 & 179 & 1.9488 & 102 & 0.9632 \\
\hline 5 & $10^{-6}$ & $\frac{1}{\sqrt{n+1}}$ & 31 & 0.2880 & 29 & 0.2712 & 18 & 0.1919 \\
\hline 5 & $10^{-6}$ & $\frac{1}{\log (n+2)}$ & 19 & 0.1909 & 24 & 0.2338 & 13 & 0.1279 \\
\hline 5 & $10^{-6}$ & $\frac{1}{(n+1) \log (n+3)}$ & 319 & 4.1638 & 385 & 5.1718 & 123 & 1.1854 \\
\hline 5 & $10^{-6}$ & $\frac{\log (n+3)}{n+1}$ & 139 & 1.2722 & 135 & 1.3614 & 77 & 0.7494 \\
\hline 5 & $10^{-6}$ & $\frac{1}{\log \log (n+20)}$ & 28 & 0.2564 & 83 & 0.7783 & 18 & 0.1797 \\
\hline
\end{tabular}

Table 1: The experimental results for Figures 1-6.

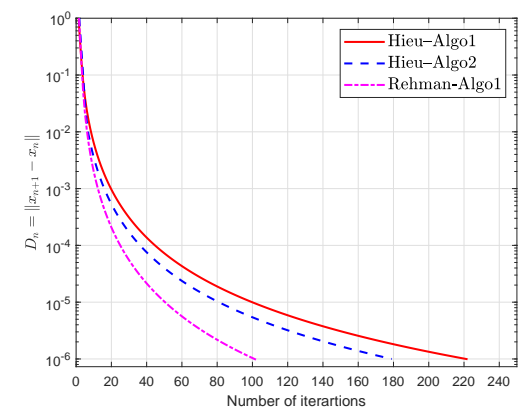

Figure 1: Equilibrium model 4.1 when $\lambda_{n}=\frac{1}{n+1}$.

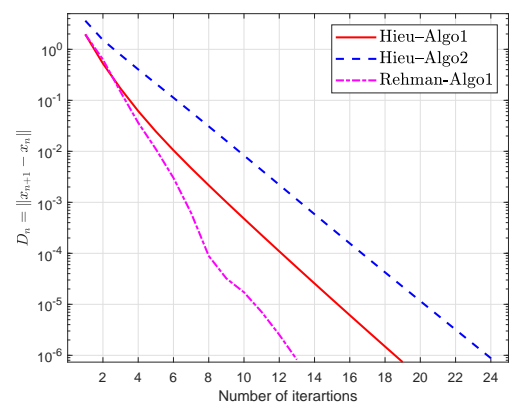

Figure 3: Equilibrium model 4.1 when $\lambda_{n}=\frac{1}{\log (n+2)}$.

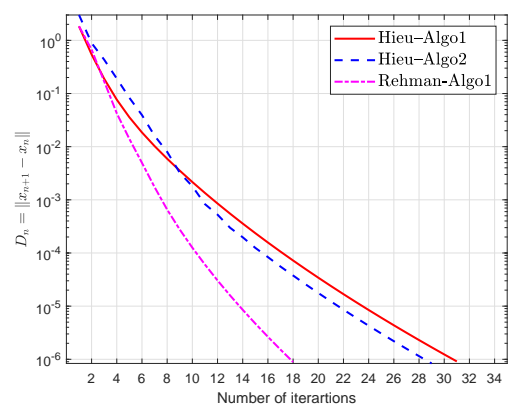

Figure 2: Equilibrium model 4.1 when $\lambda_{n}=\frac{1}{\sqrt{n+1}}$.

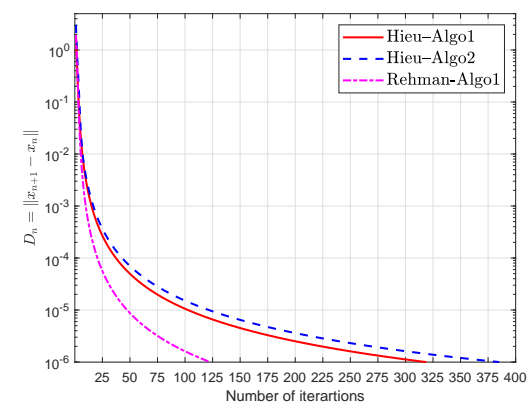

Figure 4: Equilibrium model 4.1 when $\lambda_{n}=\frac{1}{(n+1) \log (n+3)}$. 


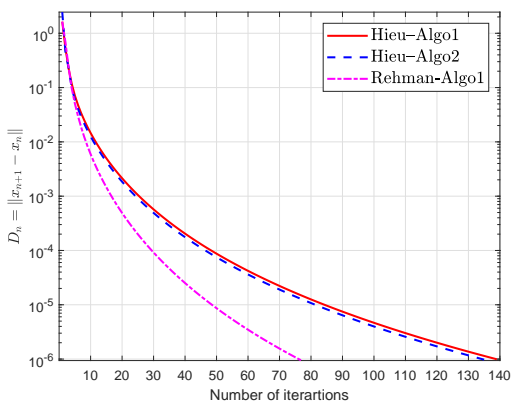

Figure 5: Equilibrium model 4.1 when $\lambda_{n}=\frac{\log (n+3)}{n+1}$. Figure 6: Equilibrium model 4.1 when $\lambda_{n}=\frac{1}{\log \log (n+20)}$.

\section{Conclusion}

In this study, we have established a new method by incorporating an inertial term with an extragradient method for solving a family of strongly pseudomonotone equilibrium problems. The prospective method requires a sequence of diminishing and non-summable stepsizes and the proposed method could be carried out without previous knowledge of the modulus of strong pseudomonotonicity and the Lipschitz-type constant of a cost bifunction. Two numerical experiments were presented to demonstrate the computational performance of the method in comparison to alternative existing methods. Such numerical results have confirmed that the method with inertial effects contributes to perform better than without inertial effects.

\section{Acknowledgment}

Habib ur Rehman has received support from "Petchra Pra Jom Klao Ph.D. Research Scholarship from King Mongkut's University of Technology Thonburi (Grant No.39/2560)". Nuttapol Pakkaranang thanks the "Royal Golden Jubilee Ph.D. (RGJ-PHD) Program (Grant No. PHD/0205/2561)". Nopparat Wairojjana was partially supported by Valaya Alongkorn Rajabhat University under the Royal Patronage, Thailand.

\section{References}

[1] J. Abubakar, P. Kumam, H. ur Rehman, A. H. Ibrahim, Inertial iterative schemes with variable step sizes for variational inequality problem involving pseudomonotone operator, Mathematics, 8 (2020), 25 pages. 1

[2] J. Abubakar, K. Sombut, H. ur Rehman, A. H. Ibrahim, An accelerated subgradient extragradient algorithm for strongly pseudomonotone variational inequality problems, Thai J. Math., 18 (2020), 166-187. 1

[3] M. Adeel, K. A. Khan, D. Pečarić, J. Pečarić, Generalization of the Levinson inequality with applications to information theorey, J. Inequal. Appl., 2019 (2019), 19 pages. 1

[4] F. Alvarez, H. Attouch, An inertial proximal method for maximal monotone operators via discretization of a nonlinear oscillator with damping, Set-Valued Anal., 9 (2001), 3-11. 2.3

[5] H. H. Bauschke, P. L. Combettes, Convex Analysis and Monotone Operator Theory in Hilbert Spaces, Springer, New York, (2017). 2.4

[6] A. Beck, M. Teboulle, A fast iterative shrinkage-thresholding algorithm for linear inverse problems, SIAM J. Imaging Sci., 2 (2009), 183-202. 1

[7] M. Bianchi, S. Schaible, Generalized monotone bifunctions and equilibrium problems, J. Optim. Theory Appl., 90 (1996), 31-43. 2.1

[8] E. Blum, From optimization and variational inequalities to equilibrium problems, Math. Student, 63 (1994), 123-145. 1, 2.1

[9] P. L. Combettes, S. A. Hirstoaga, Equilibrium programming in hilbert spaces, J. Nonlinear Convex Anal., 6 (2005), 117-136. 1

[10] S. Dafermos, Traffic equilibrium and variational inequalities, Transportation Sci., 14 (1980), 42-54. 1

[11] M. C. Ferris, J. S. Pang, Engineering and economic applications of complementarity problems, SIAM Rev., 39 (1997), 669-713. 1

[12] S. D. Flam, A. S. Antipin, Equilibrium programming using proximal-like algorithms, Math. Programming, 78 (1996), 29-41. 1 
[13] F. Giannessi, A. Maugeri, P. M. Pardalos, Equilibrium problems: nonsmooth optimization and variational inequality models, Springer, New York, (2001). 1

[14] D. V. Hieu, Parallel extragradient-proximal methods for split equilibrium problems, Math. Model. Anal., 21 (2016), 478501. 1

[15] D. V. Hieu, New extragradient method for a class of equilibrium problems in Hilbert spaces, Appl. Anal., 97 (2017), 811-824. 1, 1

[16] D. V. Hieu, Convergence analysis of a new algorithm for strongly pseudomontone equilibrium problems, Numer. Algorithms, 77 (2018), 983-1001. 1, 1

[17] A. N. Iusem, W. Sosa, Iterative algorithms for equilibrium problems, Optimization, 52 (2003), 301-316. 1

[18] I. V. Konnov, Application of the proximal point method to nonmonotone equilibrium problems, J. Optim. Theory Appl., 119 (2003), 317-333. 1

[19] I. Konnov, Equilibrium models and variational inequalities, Elsevier B. V., Amsterdam, (2007). 1

[20] A. Krylatov, V. Zakharov, T. Tuovinen, Optimization Models and Methods for Equilibrium Traffic Assignment, Springer, Cham, (2020). 1

[21] X. Li, A. Hussain, M. Adeel, E. Savas, Fixed point theorems for $\mathrm{Z}_{\theta}$-contraction and applications to nonlinear integral equations, IEEE Access, 7 (2019), 120023-120029. 1

[22] E. Ofoedu, Strong convergence theorem for uniformly l-lipschitzian asymptotically pseudocontractive mapping in real Banach space, J. Math. Anal. Appl., 321 (2006), 722-728. 2.5

[23] B.T. Polyak, Some methods of speeding up the convergence of iteration methods, U.S.S.R. Comput. Math. Math. Phys., 4 (1964), 1-17. 1

[24] T. D. Quoc, P. N. Anh, L. D. Muu, Dual extragradient algorithms extended to equilibrium problems, J. Global Optim., 52 (2011), 139-159. 1

[25] S. Takahashi, W. Takahashi, Viscosity approximation methods for equilibrium problems and fixed point problems in Hilbert spaces, J. Math. Anal. Appl., 331 (2007), 506-515. 1

[26] J. V. Tiel, Convex analysis: an introductory text, Wiley, New York, (1984). 2.2

[27] D. Q. Tran, M. L. Dung, V. H. Nguyen, Extragradient algorithms extended to equilibrium problems, Optimization, 57 (2008), 749-776. 1, 4.1

[28] H. ur Rehman, D. Gopal, P. Kumam, Generalizations of darbo's fixed point theorem for new condensing operators with application to a functional integral equation, Demonstr. Math., 52 (2019), 166-182. 1

[29] H. ur Rehman, P. Kumam, A. B. Abubakar, Y. J. Cho, The extragradient algorithm with inertial effects extended to equilibrium problems, Comput. Appl. Math., 39 (2020), 26 pages. 1

[30] H. ur Rehman, P. Kumam, I. K. Argyros, N. A. Alreshidi, W. Kumam, W. Jirakitpuwapat, A self-adaptive extragradient methods for a family of pseudomonotone equilibrium programming with application in different classes of variational inequality problems, Symmetry, 12 (2020), 27 pages. 1

[31] H. ur Rehman, P. Kumam, I. K. Argyros, W. Deebani, W. Kumam, Inertial extra-gradient method for solving a family of strongly pseudomonotone equilibrium problems in real hilbert spaces with application in variational inequality problem, Symmetry, 12 (2020), 24 pages. 1

[32] H. ur Rehman, P. Kumam, Y. J. Cho, Y. I. Suleiman, W. Kumam, Modified popov's explicit iterative algorithms for solving pseudomonotone equilibrium problems, Opti. Methods Soft., 2020 (2020), 1-32. 1

[33] H. ur Rehman, P. Kumam, Y. J. Cho, P. Yordsorn, Weak convergence of explicit extragradient algorithms for solving equilibirum problems, J. Inequal. Appl., 1 (2019), 25 pages. 1

[34] H. ur Rehman, P. Kumam, S. Dhompongsa, Existence of tripled fixed points and solution of functional integral equations through a measure of noncompactness, Carpathian J. Math., 35 (2019), 193-208. 1

[35] H. ur Rehman, P. Kumam, W. Kumam, M. Shutaywi, W. Jirakitpuwapat, The inertial sub-gradient extra-gradient method for a class of pseudo-monotone equilibrium problems, Symmetry, 12 (2020), 25 pages. 1 